\title{
The Overall Reform Experiment of Elementary and Middle School Education An Exploration of Education Reform
}

\author{
Hongxun Zhang \\ Zhengzhou No.12 High School, Jiangshan Road, Guoji Road, Zhengzhou 450000, Henan, China \\ Correspondence to: Hongxun Zhang, E-mail: zhx630@139.com \\ DOI: https://doi.org/10.15354/si.21.re212 \\ The author declares no competing interest.
}

The overall reform experiment of elementary and middle school education is a reform exploration that touches the whole process of education. Horizontally, it includes various educational factors within the school and vertically includes multiple educational stages. This experiment is based on the overall idea, from the beginning of the experiment in some areas to the whole of China, and systematically designs and comprehensively reforms the various factors that constitute school education at multiple stages. Starting from the background of the overall reform experiment, this paper elaborates on the experiment's content, history, and impact to objectively and truthfully summarize the experiment, inspire most educators, and explore practical methods for improving the experiment quality education.

Keywords: Elementary and Middle School Education; Education Reform; Educational Experiment Science Insights, 2021 September 29; Vol. 38, No. 5, pp.326-331.

() 2021 Insights Publisher. All rights reserved.

Creative Commons Non Commercial CC BY-NC: This article is distributed under the terms of the Creative Commons Attribution-NonCommercial 4.0 License which permits non-commercial use, reproduction and distribution of the work without further permission provided the original work is attributed by the Insights Publisher.

I $\mathrm{N}$ the late 1970 s and early 1980 s, the situation at home and abroad changed dramatically. Internationally, the rapid development of the scientific and technological revolution in developed countries has penetrated social production and life, causing a change in the demand for talent training. Cultivating high-quality talents with extensive knowledge and independent innovation capabilities has become the key to education reform. In response to this, many countries have launched educational reforms and put forward overall reform plans. For example, the report A Nation at Risk: The Imperative for Educational Reform promulgated by the U.S. National Commission on Excellence in Education in 1983 has established the dominant position of academic disciplines and strengthened the unity of curriculum structure. The Seven Reforms Needed in Education proposed by Japan enhances the connection between schools and society and diversifies the school system and educational content (1). In China, economical construction has become the center of all work, and education has been brought to an unprecedentedly important position. During this period, the educational reform carried out educational reform experiments from the perspective of the historical value and realistic value of traditional culture and combined with foreign advanced educational thoughts. As a result, a large number of single-subject teaching reform experiments in elementary and middle schools have been launched, such as the "asynchronous teaching method" of Shifa Lei and the "concentrated literacy of Chinese" (2).

However, this single-subject education reform experiment has limitations. The educational experiment that focuses only on the part and ignores the whole increases the overall coordination of school work and affects students' knowledge structure's improvement and overall development. In 1980, Professor Fonian Liu, a famous Chinese educator, said: "Education is complex system engineering. Individual experiments are not enough to reveal all objective laws, but comprehensive overall research must be done." Based on this, The Education Department of East China Normal University established the "Elementary 
School Comprehensive Experimental Group" in 1981. It carried out the "Comprehensive Experiment of Elementary School Students' Comprehensive Development" with a teaching class attached to its elementary school, later renamed the "Comprehensive Elementary Education Experimental Group." In 1983, the experimental team carried out a repeated experiment (3).

Since then, similar experiments have been carried out in Beijing, Hangzhou, Hubei, and other places. The Beijing Institute of Educational Science and Beijing Hongmiao Elementary School launched the "Educational Experiment on the Comprehensive Development of Elementary School Students." The Education Department of Hangzhou University and Hangzhou Tianchang Elementary School jointly launched the "Comprehensive Experiment on Optimal Development of Elementary School Students." The Department of Education of Central China Normal University implemented the "Experiment on the Reform of the Overall Structure of Elementary Education" in Xiantao Normal Elementary School in Hubei Province. After that, experimental teams from all over the country held annual experience exchanges and problem seminars to jointly explore the path of reform experiments, which promoted the development of the overall reform experiment nationwide (3).

\section{Experimental Contents}

The overall reform of elementary and middle school education is aimed at improving the overall function of educational activities, focusing on optimizing the links between the main elements of the educational activity system, between the parts and the whole, and between the educational system and the environment, and achieve an educational experiment to improve the overall functional purpose (4). The general idea is the core of the investigation, which is to increase the overall function by optimizing the educational structure.

\section{Theoretical Basis}

There are three main ideas for understanding and researching the theoretical basis of the overall reform experiment in elementary and middle schools: system science theory, educational science theory, and quality education thought.

\section{System Science Theory}

Most of the overall reform experiment and related papers focus on the guiding role of system theory in the comprehensive reform experiment. Ludwig von Bertalanffy, the founder of system theory, put forward the view that "the whole is greater than the sum of parts," that is, the sum of the functions of each part and the interconnected functions of each piece can make the system as a whole maximize its function (5). This provides educators with a new idea of the overall reform experiment, that is, the comprehensive reform experiment in elementary and middle schools is not a simple addition of single-factor experiments, but a structure composed of interrelationships and interactions between various elements of the experiment to give play to the system structure with its optimized function (1). The "Overall Optimal Education Theory" proposed by Hangzhou Tianchang Elementary School and Hangzhou University Education Comprehensive Experimental Group is based on this theory. The optimized combination of the subject system, activity system, and environment in school education has a particular educational impact, and the physical and mental development of students is fully optimized.

\section{Educational Science Theory}

In practice, the overall reform experiment absorbs many theoretical results of educational science extensively and timely to enrich its theoretical basis, including pedagogy, educational psychology, educational management, etc. Taking educational psychology as an example, the concept of "non-intellectual factors" has attracted the attention of educators, thereby promoting educators to pay attention to the cultivation of students' interests and personalities. If only focusing on the intellectual factors and ignoring the non-intellectual factors, students will become "nerds" instead of fully developed people. Experiments absorbing this theoretical basis include the "Happy Education" launched by Chengdu Longjiang Road Elementary School and the "Hope Education" of Wuhan Liangdao Street Middle School (1)

\section{Quality Education Thought}

The idea of quality education is a strategic measure based on the educational needs of modern science and technology, social economy, and human development. From the perspective of educational teleology, quality education shows that education should promote the overall development of students' quality, focusing on the unity of students' commonality and individuality. This clarifies the purpose and content of the experiment for the comprehensive reform (1). At the stage of the experiment's theme development, in the 1990s, education became the focus of research. As a result, the thought of quality education became the critical theoretical basis for most school reforms.

\section{Experiment Requirements}

(i) The purpose, time, place, and personnel of the experiment must be clear, and be integrated, and comprehensive;

(ii) Make the relevant elements in the whole form an optimized combination structure, and pay attention to the control of non-experimental factors;

(iii) The overall function achieves the best combination effect;

(iv) Experimental methods and detection methods must be comprehensive, scientific, and feasible;

(v) Establish a general concept and carry out overall design;

(vi) Improve the statistical analysis of experimental data, and study the genuine causal relationship between experimental factors and experimental indicators;

(vii) Review the experimental results and make a theoretical summary in time (6).

\section{Experimental Characteristics}

The phases and modes of the experiment are different from place to place, and the forms and effects shown are also various. However, the overall reform experiment has certain commonalities, with the following characteristics: 


\section{Integrity}

The education overall reform experiment of elementary and middle school systematically design and comprehensively reform the various factors that constitute school education at different stages of middle school, elementary school, and pre-school. Horizontally, it requires the overall combination of various educational aspects and vertically requires the systematic connection of training objectives at all levels. Thus, it is a multi-faceted, multi-series, multi-factor, multi-functional, multi-level reform experiment that touches the entire process of education (6).

\section{Subjectivity}

The overall reform experiment insists on the student's dominant position. However, the educational process is a process of bilateral activities between teachers and students. Therefore, in the process of education, it is necessary to recognize the dominant position of teachers and highlight the subjectivity of students. Thus, the experimental design fully reflects that educators' master students' psychological changes and age characteristics, understand and respect students, mobilize students' enthusiasm and initiative in learning and development, and provide students with time and opportunities to fully demonstrate themselves (1).

\section{Practical}

In the overall reform experiment, the educational activities designed by the school are varied. It involves not only in-class and school activities but also includes extracurricular and out-of-school activities. These activities enrich students' understanding of themselves and the world by promoting students' extensive contact with society and different types of people or things. In the course of practice, students' hands-on ability is strengthened, combining learning with practice (1).

\section{Experiment Stages}

The development of the overall reform experiment was brewed in the late 1970s, emerged in the 1980s, continued to develop afterward, and was widely promoted in the early 1990s. It can be divided into four stages: the stage of gestation and rise; the stage of active development; the stage of promotion and summary; the stage of theme development.

\section{The Stage of Gestation and Rise (The Late 1970s-1985)}

The experiment in this period had the characteristics of "raising questions, beginning to form topics and a small number of schools making a preliminary exploration of the overall reform" (7). Educational researchers investigated and studied the status quo of education and believed that the overall reform experiment was imperative. They reflected on the teaching reform experiment of a single subject and single item and then spontaneously explored the path of the comprehensive reform experiment of elementary and middle schools. The experiment sites were mainly in Shanghai, Beijing, Hangzhou, Hubei, and first-year students.

The Shanghai area was hosted by the experimental team of the Department of Education of East China Normal University. A first-grade class enrolled in the elementary school affiliated to
East China Normal University in 1981 was selected as the experimental object. A five-year comprehensive overall experiment was carried out (8). After a year of investigation, research, and preparation, the Beijing Institute of Education and Science put forward the "Elementary School Students' Comprehensive Development Educational Experiment Plan" inspired by the "Three Theory" thought. The Hongmiao Elementary School in Xicheng District, Beijing, was selected as the experimental site, and experimental and comparative classes were set up among the first-year students. They entered the school in September 1983. Thus, start the experiment with a cycle of six years (9). The Education Department of Hangzhou University and Hangzhou Tianchang Elementary School formed a comprehensive experimental group to carry out the "Comprehensive Experiment on Optimal Development of Primary School Students." After visiting elementary schools in Shanghai and Hangzhou, the experimental team from the Department of Education of Central China Normal University cooperated with more than a dozen elementary schools in Hubei to carry out the "Elementary Education Overall Structure Reform Experiment" (10).

Since 1984, researchers in these areas have established the "Collaborative Group for Research on Overall Reform." The collaborative group exchanges experience every year, and the heads of educational institutes and schools in some regions across the country heard the news and jointly explored the path of school reform experiments, which played a particular role in promoting the development of overall reform experiments in China (3). At the same time, it also laid a good foundation for the subsequent comprehensive reform experiment.

\section{The Stage of Active Development (1985-1988)}

The overall reform experiment of elementary and middle schools was based on the previous ones, and there was a regional, school-wide comprehensive reform experiment. However, after the Central Government of China passed the "Decision on Educational System Reform," the issue of overall educational structural reform became the focus of educational experimentation (11). Thus, the comprehensive education reform experiment has gradually become a trend of nationwide education experiments.

Beijing, Shanghai, Hangzhou, and Wuhan have carried out concentrated and in-depth thematic exploration experiments based on previous experiments. Taking Hangzhou's "Comprehensive Experiment on Optimal Development of Elementary School Students" as an example, the experimental team of the Education Department of Hangzhou University expanded the scope of the experiment after achieving initial results at Hangzhou Tianchang Elementary School. In 1986, Xuejun Elementary School carried out the "Comprehensive Experiment of Elementary School Class Management"; in 1987, the experimental team took the Gongshu District Experimental Elementary School as the experimental object and carried out the teaching experiment of "Integrity, Cooperation, and Optimization"; The rectification experiment of "Promoting the Optimal Development of Middle School Students' Personality" is carried out in China, which is also known as the follow-up experiment of Hangzhou Tianchang Elementary School (1). 
The overall reform experiment in other parts of China in cludes the overall reform of the school's internal system, the overall reform of connecting the school's external system, and the comprehensive overall reform experiment involving the entire county and city. For example, the First Elementary School of Heping Street, Heping District, Shenyang City, Liaoning Province, started a rectification experiment of "Moral Education, Teaching Methods, and Activities Together" in 1985. The elementary and middle schools in Guangxi carry out overall reform planning and practice from teaching ideas to teaching content, teaching methods, teaching methods, and examination methods. In 1987, Ningbo City launched the "Educational Experiment on the Overall Optimization of Rural Elementary Schools" with the township as the implementing unit (1).

Researchers made more in-depth theoretical discussions on the related theories of system science, put their in-depth understandings into experiments in combination with the actual situation, and carried out many special studies. As a result, the concept and nature of the overall reform experiment had been fully explored, which had obvious significance in guiding practice for thinking the research itself.

\section{The Stage of Promotion and Review (1988-1993)}

In July 1988, the overall reform seminar of elementary and middle schools was held in Beijing Yucai School. After the meeting, the "China Education Society Elementary and Middle Schools Overall Reform Professional Committee" was established. This marks the beginning of the research on the overall reform experiment of elementary and middle schools into the in-depth stage of cooperation and promotion between the private sector and the government.

With the support of the State Education Commission and the Chinese Education Society, the experiment formed a model of collaboration between professional committees and local governments. The special committee's Elementary and Middle Schools Overall Reform Brief in April 1991 published experimental research results. In addition, they held six annual academic conferences in Beijing, Shanghai, Tianjin, and other places. It has made a significant contribution to the in-depth study of the overall reform experiment.

This stage's reformatted both development and reflection, and significant changes have taken place in theoretical research and practice. For example, Niu et al. reflected on the problems of the selection mechanism and the education management system that emerged during the experiment and proposed solutions (12). Lei and Yang have a clear understanding of the educational concept, educational management system, and nature of the overall reform experiment of elementary and middle schools (4). In addition, many schools have begun to shift the focus of the investigation from the educational work of the research school to the object of education; that is, they have started to pay attention to the development of student's personalities, showing that the experimental research methodology has shifted from a holistic view to a critical theory.

\section{The Stage of Theme Development (1993-2000)}

After the "China Education Reform and Development Program" (February 1993) was promulgated, the overall reform experiment of elementary and middle schools has made further progress. The most prominent feature of this stage of the experiment is the shift from thematic research to thematic research and development; that is, the focus of the overall reform experiment of elementary and middle schools has shifted to focus on the subjectivity of students. The development of subjectivity in this period was based on people's further understanding of the relationship between overall reform and quality education. As a result, educators realize that quality education is the purpose and content of comprehensive reform experiment, and overall reform experiment is the method and process of quality education (1). On this basis, many educators emphasize quality education, laying the foundation for implementing and developing quality education.

\section{Influence of the Experiment}

The elementary and middle schools overall reform experiment is a representative experiment in the history of contemporary Chinese educational experiments. Therefore, to explore the successful path of general education reform, put forward feasible schemes for improving educational efficiency, and provide valuable experience for subsequent educational experiments.

The overall reform experiment of elementary and middle schools improved educational efficiency in practice and theory. In terms of curriculum, the school has formed a curriculum model focusing on essential quality. Basic courses such as Chinese and mathematics are longer and arranged in the morning, which guarantees students' basic knowledge. In terms of practice, the school's vertical and horizontal connections are closed. The experiment is based on overall thinking, which promotes the relationship between the various educational elements within the school and strengthens the bond between schools, families, and society. Therefore, the school system, courses, textbooks, and subject teaching methods have been redesigned accordingly. As a typical example, Shanghai Experimental School has established the "Ten-Year Consistent System" of the longitudinal school system reform, which effectively alleviates disconnection between elementary and elementary school and senior high schools. In terms of horizontal reforms, the school adopts a "block structure setting curriculum," dividing the ten-year curriculum into three primary modules: compulsory, elective, and extracurricular activities; to promote the overall arrangement of teaching plans and optimize the curriculum structure (1). In learning, students' knowledge is well connected, and they can also apply what they have learned to improve their abilities in all aspects. In terms of evaluation, the school pays more attention to the subjectivity of students, so it has formed an educational evaluation model that focuses on the overall quality of student development. Furthermore, the optimized curriculum structure and evaluation model could be considered as the precondition for better development of the follow-up quality education.

However, the overall reform experiment of elementary and middle schools have not been smooth sailing. At the end of the 1990s, the investigation entered a "bottleneck period." Since the overall reform experiment has formed a national upsurge, some schools regard it as a typical reform work and completely copy 
the reform model of the successful experimental school, which leads to the failure of their educational experiment. In addition, due to the extensive content of the overall education reform experiment, some schools lack specific understanding and blindly carry out reforms, failing to achieve ultimate success. However, with the change of research objects, the overall education reform has been transformed into quality education. The experiment's practical methods and theories lay a good foundation for quality education and promote the development of quality education. To a certain extent, it inspires most educators to pay attention to the prominent status of students in the process of practice and proceed from reality to improve the efficiency of education effectively.

\section{Implication}

China's education reform in is a complicated social event that has been lasting for decades (13). As mentioned above, from the late 1970 s to the 2000s, it has experienced four stages. Given the great changes in the social environment posed great requirement on education, i.e., adapting the social needs with more attention should be paid to follow the rule inside the education reform, so as to provide better training for students.

The education reform has concentrated on the teaching reform for a single subject, regional reform, students' individuality development, and subjectivity development. The educational experiments also have been conducted in this context, and the findings reflected the new educational theory proposed in the early 2000s.

Taking the school system reform as an example, Shanghai Experimental School has successfully tried the "Six-Year," "Eight-Year," "Nine-Year," and "Ten-Year" Systems. Eventually, the "Ten-Year System" was promoted based on the actual situa- tion of the disconnection of the previous semesters and the difficulty in guaranteeing practical activities.

However, nowadays, the reform of basic education is eager for quick success. Some educational experiments lack in-depth reflection and long-lasting insights, and without effective results obtained. The overall reform experiment in the specific experimental design and operation helped to promote the optimization of the comprehensive reform experiment overall structure. To a certain extent, it drove the social attention to the overall reform experiment. Initially, the overall reform experiment was only spontaneously carried out in some areas. As the investigation continued, a special committee was established to cooperate with the government to develop the overall reform experiment further. After that, the school has a close relationship with the social education force like enterprises, research institutions, and non-governmental organizations. Schools should actively promote connections with these social forces and collaborate with them inside and outside the school (1). In this way, the social factors were further promoted to the integration in the education system, and gradually transfer from "social education" to "education for all" (14).

Moreover, the process of education reform also promotes the reflection on the evaluation of reform and stimulates the development of the construction of educational facilities. While the reason lies in the guidance document released by the relevant departments, where exists the confusion in providing the path of the extended development of education that affects the reform by the external standards (15). For further construction of education, the internal criteria for the education development need to be established, so that the construction effects of education could be evaluated much easier and better.

\section{References}

1. Yang L. Research on China's "Experiment on Overall Reform of Primary and Secondary Schools" (1978-2000) Dissertation; China West Normal University. 2015. (Chinese) http://cdmd.cnki.com.cn/Article/CDMD-10638-10159 96272.htm

2. Yu BF, Zeng R. Chronicles of modern Chinese educational experiments (2). Educ Res Exp 1999; 18(2):68-71. (Chinese) https://kns.cnki.net/kcms/detail/detail.aspx?dbcode= CJFD\&dbname $=$ CJFD9899\&filename=YJSY199902 015\&v=JEMuZwUaCmi\%25mmd2FylRCrwSos7HP0 9Q7nqmrA5rrHKpqNNsLWILg5WmWajH61 nUhhyq

3. Zhang $X$. A case study: the overall reform experiment of primary and secondary schools from educational

experiment methodology. Educ Sci Res 2000; 11(1):46-54. (Chinese) http://www.cnki.com.cn/Article/CJFDTotal-JYKY2000 01008.htm

4. Lei S, Yang XW. Perplexity and reflection on the overall education reform experiment. Educ Res Exp 1993; 12(3):1-6. (Chinese) http://www.cnki.com.cn/Article/CJFDTotal-YJSY1993 03000.htm

5. Wang DR. Re-discussion on the scientization of the overall education reform experiment. Educ Sci Res 1990; 1(6):1-5+12. (Chinese) http://www.cnki.com.cn/Article/CJFDTotal-JYKY1990 06000.htm

6. Gu MY. Dictionary of Education. Shanghai: Shanghai 
Education Press. 1990. (Chinese)

7. Ye L. "An analysis of the fundamental motivation and route of the research and development of the overall reform of primary and secondary schools in China," Collected Works on the Overall Reform of Primary and Secondary Schools (Volume 3). Harbin: Harbin Press. 2003. (Chinese)

8. Wu HZ, Chen XC, Lu JP, Sheng YX, Wu YR, Zhang YX. A practical summary of the comprehensive experiment of primary education. Educ Res Exp 1987; 6(2):50-59. (Chinese) http://www.cnki.com.cn/Article/CJFDTotal-YJSY1987 02010.htm

9. Experimental Research Group of Beijing Institute of Educational Science, Experimental Research Group of Hongmiao Primary School, Xicheng District, Beijing. Realize the overall optimization of education and promote the overall development of students-the experimental report of "Primary School Students' All-round Development Educational Experiment." Educ Sci Res 1990; 1(2):8-17+36. (Chinese) http://www.cnki.com.cn/Article/CJFDTotal-JYKY1990 03004.htm

10. Kuang XM. A review of the experimental work of the overall structure reform of primary education in the past year. Educ Res Exp 1984; 3(2):100-106+61. (Chinese)

http://www.cnki.com.cn/Article/CJFDTotal-YJSY1984

\section{2.htm}

11. Ge MG, Xu Q. Introduction to primary and secondary educational experiments. Beijing: University of Science and Technology of China Press. 2008. (Chinese)

12. Niu $Y Z, H u Z Q$, Rou G. Optimizing the social environment to promote the overall reform-the confusion and thinking of the overall reform. Theory Pract Educ 1991; 10(4):7-10. (Chinese) http://www.cnki.com.cn/Article/CJFDTotal-JYLL19910 4002.htm

13. Wu KN. Why is education reform so difficult in China? J East Chin Normal Univ (Educ Sci) 2010; 28(4):10-19+36. (Chinese) DOI: https://doi.org/10.16382/j.cnki.1000-5560.2010.04.00 $\underline{5}$

14. Li ZT. The "education for all" of contemporary education development. Educ Res 2020; 41(6):4-13. (Chinese)

http://www.cnki.com.cn/Article/CJFDTotal-JYYJ2020 06002.htm

15. Wu QH. Several phenomena needing attention in the evaluation of educational reform. Res Educ Develop 2019; 39(Z2):103-107. (Chinese) DOI: https://doi.org/10.14121/i.cnki.1008-3855.2019.z2.01 $\underline{7}$ 